\title{
Study of colorectal mortality in the Andalusian population
}

\author{
Aurelio Cayuela ${ }^{1,2}$, Susana Rodríguez-Domínguez ${ }^{3}$, Marta Garzón-Benavides ${ }^{4}$, Ángeles Pizarro-Moreno ${ }^{4}$ \\ Álvaro Giráldez-Gallego ${ }^{4}$ and Carmen Cordero-Fernández ${ }^{4}$ \\ ${ }^{1}$ Department of Clinical Documentation. Hospital Universitario Virgen del Rocío. ${ }^{2}$ Public Health Emergency \\ Service Company of Andalusia. ${ }^{3}$ Pino Montano Health Center. ${ }^{4}$ Department of Digestive Diseases. Clinical Service. \\ University Hospital Virgen del Rocío. Seville, Spain
}

\begin{abstract}
Objectives: to provide up-to-date information and to analyze recent changes in colorectal cancer mortality trends in Andalusia during the period of 1980-2008 using joinpoint regression models.

Patients and methods: age- and sex-specific colorectal cancer deaths were taken from the official vital statistics published by the Instituto de Estadística de Andalucía for the years 1980 to 2008. We computed age-specific rates for each 5-year age group and calendar year and age-standardized mortality rates per 100,000 men and women. A joinpoint regression analysis was used for trend analysis of standardized rates. Joinpoint regression analysis was used to identify the years when a significant change in the linear slope of the temporal trend occurred. The best fitting points (the "joinpoints") are chosen where the rate significantly changes.

Results: mortality from colorectal cancer in Andalusia during the period studied has increased, from 277 deaths in 1980 to 1,227 in 2008 in men, and from 333 to 805 deaths in women. Adjusted overall colorectal cancer mortality rates increased from 7.7 to 17.0 deaths per 100,000 person-years in men and from 6.6 to 9.0 per 100,000 person-years in women Changes in mortality did not evolve similarly for men and women. Age-specific $\mathrm{CRC}$ mortality rates are lower in women than in men, which imply that women reach comparable levels of colorectal cancer mortality at higher ages than men.

Conclusions: sex differences for colorectal cancer mortality have been widening in the last decade in Andalusia. In spite of the decreasing trends in age-adjusted mortality rates in women, incidence rates and the absolute numbers of deaths are still increasing, largely because of the aging of the population. Consequently, colorectal cancer still has a large impact on health care services, and this impact will continue to increase for many more years.
\end{abstract}

Key words: Colorectal cancer. Mortality. Regression analysis.

Received: $22-11-10$

Accepted: 04-02-11.

Correspondence: Marta Garzón Benavides. Servicio de Aparato Digestivo. Hospital Universitario Virgen del Rocío. Avda. Manuel Siurot, s/n. 41013 Seville, Spain.

e-mail: mgarzonb@hotmail.com
Cayuela A, Rodríguez-Domínguez S, Garzón-Benavides M, Piza rro-Moreno A, Giráldez-Gallego A, Cordero-Fernández C. Study of colorectal mortality in the Andalusian population. Rev Esp Enferm Dig 2011; 103: 289-293.

\section{INTRODUCTION}

Colorectal cancer (CRC) is the second most frequently occurring malignancy in the European Union (EU), and the second leading cause of cancer-related death in the Western world (1).

In Europe, CRC mortality has been declining from 13.4 to $11.5 / 100$, 000 from $1980-1984$ to $2000-2004$ in women and from 20.1 to $18.8 / 100,000$ from $1990-1994$ to 2000 2004 in men (2). This favorable trends were observed in most north and western countries (3), whereas trends were less favorable in southern (particularly Spain) and most central and eastern European countries, which had lower mortality rates in the past (4). CRC incidence among men increased moderately in most countries and markedly in Austria, Croatia, Czech Republic, Slovenia and Spain. Among women, the incidence rates were stable with some decreases in Scotland, Northern Ireland, and Poland, contrasting a clear increase in Spain (5).

In the Autonomous Community of Andalusia, in southern Spain, age-standardized CRC mortality rates increased both in men and women (6). These previous analyses were based on models of death rates within one time period (1975-2001) and yielded the average percent change assuming that rates increase or decrease with time at a constant rate, though the validity of this assumption has not been evaluated (7). The joinpoint regression model is useful for identifying and describing the occurrence of changes in different time periods throughout trends in data (8). 
Screening can reduce CRC mortality by early detection of CRC and cancer prevention by endoscopic identification and removal of advanced adenomas (9). Monitoring current CRC mortality trends should help us to evaluate the effectiveness of CRC screening programs in the future. Therefore, in preparation for any type of forthcoming CRC mass screening, the aim of this study is to provide up-to-date information and to analyze recent changes in CRC mortality trends in Andalusia during the period of 1980-2008 using joinpoint regression models (10).

\section{PATIENTS AND METHODS}

Age- and sex-specific CRC deaths -International Classification of Diseases (ICD), $9^{\text {th }}$ revision, codes 153$154 ; 10^{\text {th }}$ revision, codes C18-C21 for post-1999 deathswere taken from the official vital statistics published by the "Instituto de Estadística de Andalucía" for the years 1980 to 2008, which was the last year for which data was available at the time of the study. Populations were estimated on July $1^{\text {st }}$ of each year, based on official census information.

From the matrices of certified deaths and resident population, we computed age-specific rates for each 5-year age group and calendar year and age-standardized mortality rates per 100,000 men and women -at all ages and truncated 35-64 years- using the direct method and on the basis of the world standard population (11), and are expressed as rates/100,000 men or women.

A joinpoint regression analysis was used for trend analysis of standardized rates. Joinpoint regression analysis was used to identify the years when a significant change in the linear slope of the temporal trend occurred. The best fitting points (the "joinpoints") are chosen where the rate significantly changes. The analysis starts with the minimum number of joinpoints (e.g., 0 joinpoints, which is a straight line, on a log scale), and tests whether one or more joinpoints (up to 3) are significant and must be added to the model. The tests of significance use a Monte Carlo permutation technique. In the final model, each joinpoint (if any) informs of a significant change in trend, and an estimated annual percentage of change (EAPC) is computed by each of those trends by means of generalized linear models, assuming a Poisson distribution. The purpose of joinpoint regression is twofold. Firstly, it is useful to detect points in time where significant changes in the trends occur. Secondly, it can estimate the magnitude of changes observed at each interval. Standardized rates and their standard errors were used for estimation of these models. Populations following a Poisson distribution were used for those models using age-specific rates (12). Increment and decrement were considered to occur when the slope (coefficient) of the trend was found to be sta- tistically different from zero (two-tailed $\mathrm{p}<0.05$ ). If this was not the case, the trend was considered stable.

The computation of mortality rates and their standard errors were performed using a spreadsheet (Microsoft Excel). Joinpoint analyses were performed using the "Joinpoint" software from the Surveillance Research Program of the US National Cancer Institute (13).

\section{RESULTS}

Mortality from CRC in Andalusia during the period studied has undergone a considerable increase in absolute numbers, rising from 277 deaths in 1980 to 1,227 in 2008 in men, and from 333 to 805 deaths in women. CRC ranked second among the leading causes of cancer death in both men (12.4\% of all cancers deaths) and in women (14.9\% of all cancer deaths) in 2008.

Figure 1 gives the overall mortality rates due to CRC per 100,000 in Andalusia for the period 1980-2008, in men and women. Table I demonstrates the results of the joinpoint regression analysis (i.e. the points at which rates changed significantly) and the APC for each trend in men and women.

During the period 1980-2008, adjusted overall CRC mortality rates increased from 7.7 to 17.0 deaths per 100,000 person-years in men (EAPC: $2.6 \%, \mathrm{p}<0.05$ ) and from 6.6 to 9.0 per 100,000 person-years in women (EAPC: $1.1 \%, \mathrm{p}<0.05)$. However, changes in mortality did not evolve similarly for men and women. As can be seen in figure 1, CRC mortality trend showed significant joinpoints for both sexes: in men there was a marked increase from 1980 to 1998 (EAPC 3.7\%, p < 0.05), after which mortality rates increased more slowly (EAPC $0.8 \%$, $\mathrm{p}<0.05$ ). In women, there was a marked increase from 1980 to 1996 in mortality rates (EAPC 2.9\%; p < 0.05),

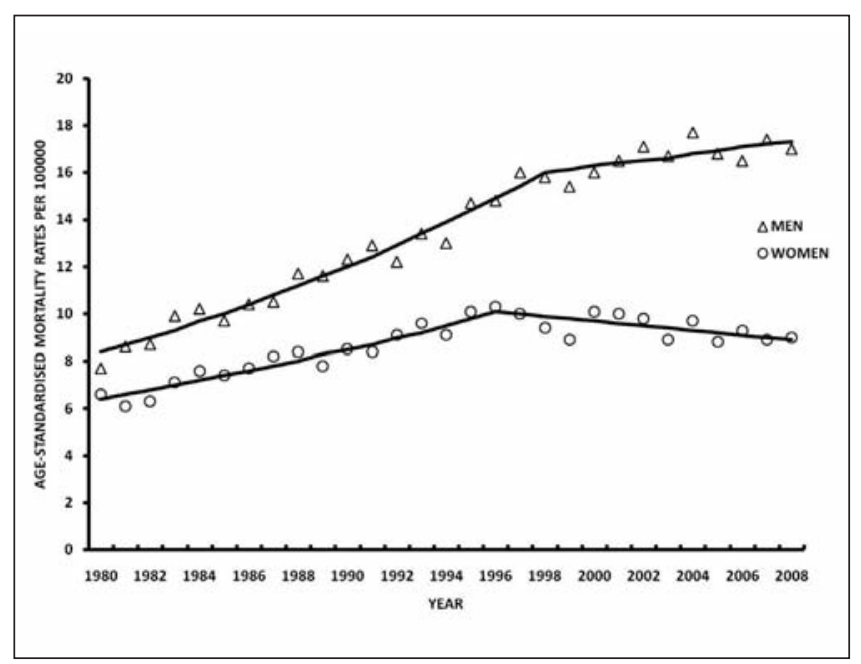

Fig. 1. Age-standardized (per 100,000 world standard) mortality rates for colorectal cancer in Andalusia (Spain), 1980-2008. 
Table I. Colorectal cancer mortality rates and joinpoint analysis (Andalusia, 1980-2008): males and females, age-specific and age-standardized

\begin{tabular}{|c|c|c|c|c|c|c|c|c|}
\hline & \multirow[b]{3}{*}{ Age groups (years) } & \multicolumn{2}{|c|}{ Rates } & \multirow{3}{*}{$\begin{array}{l}A P C \\
1980-2008\end{array}$} & \multicolumn{4}{|c|}{ Joinpoint analyses (1980-2008) } \\
\hline & & \multirow[t]{2}{*}{1980} & \multirow[t]{2}{*}{2008} & & \multicolumn{2}{|c|}{ Trend1 } & \multicolumn{2}{|l|}{ Trend2 } \\
\hline & & & & & Years & EAPC & Years & EAPC \\
\hline \multicolumn{9}{|l|}{ Men } \\
\hline & $30-39$ & 1.6 & 0.8 & -0.8 & $1980-2008$ & -0.8 & & \\
\hline & $40-49$ & 5.0 & 6.3 & 0.2 & $1980-2008$ & 0.2 & & \\
\hline & $50-59$ & 9.6 & 25.5 & $3.1^{*}$ & $1980-2002$ & $4.0^{*}$ & $2002-2008$ & -1.7 \\
\hline & $60-69$ & 33.3 & 73.4 & $3.0^{*}$ & $1980-2001$ & $4.0 *$ & $2001-2008$ & -0.4 \\
\hline & $70-79$ & 81.4 & 182.3 & $2.6^{*}$ & $1980-2004$ & $2.9 *$ & $2004-2008$ & 0.1 \\
\hline & $80+$ & 127.1 & 344.7 & $2.7^{*}$ & 1980-1995 & $5.3^{*}$ & $1995-2008$ & 0.9 \\
\hline & Crude & 8.8 & 30.6 & $4.3^{*}$ & $1980-2001$ & $5.2^{*}$ & $2001-2008$ & $1.4^{*}$ \\
\hline & ASR Overall & 7.7 & 17.0 & $2.6^{*}$ & 1980-1998 & $3.7^{*}$ & $1998-2008$ & $0.8^{*}$ \\
\hline & $\begin{array}{l}\text { ASR Truncated } \\
(35-64)\end{array}$ & 9.4 & 17.8 & $2.4^{*}$ & $1980-2002$ & $3.1^{*}$ & $2002-2008$ & -1.0 \\
\hline \multicolumn{9}{|l|}{ Women } \\
\hline & $30-39$ & 1.4 & 1.0 & -0.8 & $1980-2008$ & -0.8 & & \\
\hline & $40-49$ & 4.4 & 6.5 & 1.1 & 1980-1995 & $4.7^{*}$ & $1995-2008$ & $-2.3 *$ \\
\hline & $50-59$ & 12.9 & 18.0 & $1.5^{*}$ & 1980-1995 & $2.7^{*}$ & $1995-2008$ & 0.3 \\
\hline & $60-69$ & 28.1 & 34.4 & $1.1^{\star}$ & $1980-2001$ & $2.1^{*}$ & $2001-2008$ & $-3.3^{*}$ \\
\hline & $70-79$ & 60.3 & 76.5 & $0.8^{*}$ & 1980-1991 & $4.2^{\star}$ & $1991-2008$ & $-0.6^{*}$ \\
\hline & $80+$ & 109.4 & 186.8 & $1.7^{*}$ & $1980-2000$ & $3.1^{\star}$ & $2000-2008$ & $-2.0 *$ \\
\hline & Crude & 10.2 & 21.0 & $2.7^{*}$ & 1980-1996 & $4.6^{*}$ & $1996-2008$ & 0.5 \\
\hline & ASR Overall & 6.6 & 9.0 & $1.1^{*}$ & 1980-1996 & $2.9 *$ & $1996-2008$ & $-1.0 *$ \\
\hline & $\begin{array}{l}\text { ASR Truncated } \\
(35-64)\end{array}$ & 8.4 & 11.9 & $1.1^{*}$ & 1980-1996 & $2.7^{*}$ & $1996-2008$ & -0.9 \\
\hline
\end{tabular}

EAPC: estimated annual percentage change. *The EAPC is significantly different from $0(p<0.05)$.

followed by a decrease (APC $-1.0 \%$; $\mathrm{p}<0.05)$. The mortality sex rate ratios $(\mathrm{M} / \mathrm{F})$ increased from 1.2 in 1980 to 1.9 in 2008. Age-adjusted (35-64 years) mortality.

In men, age-adjusted (35-64 years) mortality rates increased steadily from 1980 to 2002 (APC $3.1 \%, \mathrm{p}<0.05$ ) and then leveled off. In women, similar to the pattern observed in men, rates increased from 1980 to 1996 (APC $2.7 \%, \mathrm{p}<0.05$ ) and then leveled off (Table I).

Age-specific CRC mortality rates are lower in women than in men, which imply that women reach comparable levels of CRC mortality at higher ages than men.

In both men and women, age group analysis revealed that for the entire study period, rates increased significantly in all age groups older than 50 years. No statistically significant trends were observed in the other age groups. Of interest, joinpoint analysis distinguished the occurrence of two periods in males above 50 years of age: in the first period CRC mortality rates increased and in the second period there was a leveling off in rates. In females, similar to the pattern observed in men, an initial increment was evident but followed by a decrease in rates in almost age groups older than 40 years.

\section{DISCUSSION}

Our results obtained in a Southern Spanish population show more favorable CRC mortality trends for females (decreasing) than males (less rapidly rising) in recent years. In fact, the results show a steady increase in mortality sex rate ratios during the period considered (1.2 in 1980 to 1.9 in 2008). More advantageous outcomes in women than men have also been observed in Europe over recent decades $(14,15)$.

Several factors may have affected the variations in mortality rates within the stated period, including demographic factors, differential sex exposure to major environmental risk factors (16) and in the access to health systems.

CRC is very much a cancer of the elderly (more than 94\% of the CRC deaths occur in Andalusia that are age 50 and over) and with increasing aging of the population the number of cases in the population may be expected to rise further. Unlike age, there are other risk factors that are modifiable. They include sedentary life style and obesity (17), diabetes (18), smoking (19), alcohol consumption (20), red and processed meats intake (21), especially well done meat or in direct contact with fire (22). 
In contrast, fruit and vegetables intake (23) and physical exercise (24) have been considered as protective factors. However, scarce information about the prevalence of these risk factors along time is available in Andalusia. This knowledge could help to explain, at least partially, the evolution of the disease pattern.

Primary prevention of CRC is a major health priority. The promotion of well-targeted public health campaigns for healthy eating, increased physical activity, as well as alcohol and smoking awareness, is essential in reducing incidence and therefore mortality rates in both men and women in the future. In United Kingdom, 31.5\% of CRC in men and $18.4 \%$ in women could be prevented if reasonable targets with respect to diet (reduced consumption of red meat, increased fruit and vegetables), exercise (30 min 5 days a week), reduced alcohol consumption (3 units a day for men, 2 units for women) and weight control were achieved (25).

In addition to primary prevention mass screening programs should be promoted, since it has been shown that they decrease the incidence and thus mortality from this malignancy (26). The complexity involved in the development of those screening programs is to include all the factors into which the population may be grouped according to the risk of developing CRC. Among these factors, mention may be made of the higher incidence of $\mathrm{CRC}$ in males at an earlier age and the presence of a history of CRC in first-degree relatives (27).

Health-care services reform in Andalusia has been accompanied by major improvements in the health-care system. There has been an increase in the number of physicians per 100,000 population and in the number of primary health-care centers. Although Andalusia has no organized screening program for CRC (it is planned to introduce it in 2010), the majority of hospitals offer screening with colonoscopy to high-risk individuals and it is likely that rates of informal screening have increased over the past two decades. Thus, early detection and better excision of adenomatous polyps (28) due to better access to health care and better training of endoscopist, with a consequent improved survival and to improved therapeutic protocols (29) are the most plausible explanations for the deceleration in CRC mortality trends in recent years in Andalusia, even without a mass screening program.

When it comes to interpreting our results, the limitations of mortality data must be borne in mind. To study cause-specific trends, the best approach would be to combine incidence and mortality data. Due to the lack of morbidity data in Andalusia, our analysis relied entirely on mortality data in order to satisfy the criteria of continuity and completeness (30).

A further possible limitation of the data used is linked to the quality of death registry entries. In our country, the accuracy of cancer death certificates has been studied, and deaths from cancer as a whole and leading cancer types, such as CRC, are well certified (31). Although cer- tification quality should be the same for both men and women, there are no studies, to the best of our knowledge that have assessed possible differences in death certification between sexes. In addition, the decentralization in the coding of mortality statistics in the 1980s led to an increase in the quality of these data in Andalusia $(32,33)$.

Another potential problem of data reliability is the change from ICD-9 to ICD-10 codes implemented in 1999, although this cannot explain the period effects observed because there were no relevant changes in definition of CRC (34) and the tendency of the main causes of mortality has been largely unaffected by the revisions in the ICD-10 (35). Furthermore, our study has analyzed truncated rates (35-64 years old), in which the quality of information on cause of death is better.

Although there are differences in the etiologies and epidemiology of colon and rectal cancer (36), we chose to examine colon and rectum cancers combined in order to avoid misclassification that may occur for tumors at the recto-sigmoid junction. In Andalusia, a detailed analysis confirms that malignant disease of the colon is the most frequent, accounting for $80.1 \%$ of all cases, followed by malignant diseases of the rectum $(15.4 \%)$ and rectosigmoid (4.1\%) and tumors of the anus and anal channel $(0.4 \%)$.

In conclusion, sex differences for CRC mortality have been widening in the last decade in Andalusia. In spite of the decreasing trends in age-adjusted mortality rates in women, incidence rates and the absolute numbers of deaths are still increasing, largely because of the aging of the population. Consequently, colorectal cancer still has a large impact on health care services, and this impact will continue to increase for many more years.

\section{REFERENCES}

1. Ferlay J, Autier P, Boniol M, Heanue M, Colombet M, Boyle P. Estimates of the cancer incidence and mortality in Europe in 2006. Ann Oncol 2007;18(3):581-92.

2. La Vecchia C, Bosetti C, Lucchini F, Bertuccio P, Negri E, Boyle P, et al. Cancer mortality in Europe, 2000-2004, and an overview of trends since 1975. Ann Oncol 2010;21(6):1323-60.

3. Bosetti C, Bertuccio P, Levi F, Lucchini F, Negri E, La Vecchia C. Cancer mortality in the European Union, 1970-2003, with a joint point analysis. Ann Oncol 2008;19:631-40.

4. Fernandez E, La Vecchia C, Gonzalez JR, Lucchini F, Negri E, Levi F. Converging patterns of colorectal cancer mortality in Europe. Eur J Cancer 2005;41:430-7.

5. Karim-Kos HE, De Vries E, Soerjomataram I, Lemmens V, Siesling S, Coebergh JWW. Recent trends of cancer in Europe: a combined approach of incidence, survival and mortality for 17 cancer sites since the 1990s. Eur J Cancer 2008;44:1345-89.

6. Ruiz M, Escolar A, Hermosín T. Mortality from colorectal cancer in Andalusia: findings in favor of mass screening. Rev Esp Enferm Dig 2005;97(2):104-14

7. Esteve J, Benhamou E, Raymond L. Statistical methods in cancer research. Volume IV. Descriptive Epidemiology. IARC Scientific Publications n. ${ }^{\circ}$ 128. Lyon; 1994:170-211.

8. Kim H-J, Fay MP, Feuer EJ, Midthune DN. Permutation tests for joinpoint regression with applications to cancer rates. Stat Med 2000;19:335-51. 
9. Levin B, Lieberman DA, McFarland B, Smith RA, Brooks D, Andrews KS, et al. Screening and surveillance for the early detection of colorectal cancer and adenomatous polyps, 2008: a joint guideline from the American Cancer Society, the US Multi-Society Task Force on Colorectal Cancer, and the American College of Radiology. CA Cancer J Clin 2008;58(3):130-60.

10. Kim H-J, Fay MP, Feuer EJ, Midthune DN. Permutation tests for joinpoint regression with applications to cancer rates. Stat Med 2000; 19:335-51.

11. Doll R, Smith PG. Comparison between registries: age-standardized rates. In: Waterhouse JAH, Muir CS, Shanmugaratnam K, Powell J, Peachman D, Whelan S, editors. Cancer incidence in five continents. Vol. IV. Lyon, IARC Scientific Publications; 1982(No. 42).

12. Kim HJ, Fay MP, Feuer EJ, Midthune DN. Permutation tests for joinpoint regression with applications to cancer rates. Stat Med 2000;19:335-51.

13. National Cancer Institute. Statistical Research and Applications Branch (On-line). Available at: http://srab.cancer.gov/ (23 Dec 2009, date last accessed).

14. Fernandez E, Bosetti C, La Vecchia C, Levi F, Fioreti F, Negri E. Sex differences in colorectal cancer mortality in Europe, 1955-1996. Eur J Cancer Prev 2000;9:99-104.

15. Béjar L, Gili M, Díaz V, Ramírez G, López J, Cabanillas JL, et al. Incidence and mortality by colorectal cancer in Spain during 19512006 and its relationship with behavioural factors. Eur J Cancer Prev 2009; 18:436-44.

16. Fernandez E, Bosetti C, La Vecchia C, Levi F, Fioretti F, Negri E. Sex differences in colorectal cancer mortality in Europe, 1955-1996. Eur J Cancer Prev 2000;9:99-104.

17. Larsson SC, Wolk A. Obesity and colon and rectal cancer risk: a metaanalysis of prospective studies. Am J Clin Nutr 2007;86:556-65.

18. Larsson SC, Orsini N, Wolf A. Diabetes mellitus and risk of colorectal cancer: a meta-analysis. J Natl Cancer Inst 2005;97:1679-87.

19. Botteri E, Iodice S, Bagnardi V, Raimondi S, Lowenfels AB, Maisonneuve P. Smoking and colorectal cancer: a meta-analysis. JAMA 2008;300:2765-78.

20. Cho E, Smith-Warner SA, Ritz J, van den Brandt PA, Colditz GA, Folsom AR, et al. Alcohol intake and colorectal cancer: a pooled analysis of 8 cohort studies. Ann Intern Med 2004;140:603-13.

21. Norat T, Lukanova A, Ferrari P, Riboli E. Meat consumption and colorectal cancer risk: dose-response meta-analysis of epidemiological studies. Int J Cancer 2002;98:241-56.

22. Santarrelli RL, Pierre F, Corpet DE. Processed meat and colorectal cancer: a review of epidemiologic and experimental evidence. Nutr Cancer 2008;60:131-44.
23. Norat T, Bingham S, Ferrari P, Slimani N, Jenab M, Mazuir M, et al. Meat, fish, and colorectal cancer risk: The European Prospective Investigation into Cancer and Nutrition. J Natl Cancer Inst 2005;97: 906-16.

24. Wolin KY, Yan Y, Colditz GA, Lee IM. Physical activity and colon cancer prevention: a meta-analysis. Br J Cancer 2009;100: 611-616.

25. Parkin DM, Olsen AH, Sasieni P. The potential for prevention of colorectal cancer in the UK. Eur J Cancer Prev 2009;18:179-90.

26. Consumo MdSy. Estrategia en Cáncer del Sistema Nacional de Salud. Madrid: Ministerio de Sanidad y Consumo; 2006.

27. Navarro M, Binefa G, Blanco I, Guardiola J, Rodriguez-Moranta F, Peris M,; and the Catalan Colorectal Cancer Screening Pilot Program Group. Colorectal cancer screening: strategies to select populations with moderate risk for disease. Rev Esp Enferm Dig 2009;101:85560.

28. Pizarro-Moreno A, Cordero-Fernandez C, Garzón-Benavides M, Cayuela A, Bozada-García JM, Sobrino-Rodriguez S, et al. Malignant colonic adenomas. Therapeutic criteria. Long-term results of therapy in a series of 42 patients in our healthcare area. Rev Esp Enferm Dig 2009; 101:830-6.

29. Mitry E, Bouvier AM, Esteve J, Faive J. Improvement in colorectal cancer survival: a population-based study. Eur J Cancer 2005;41: 2297-303.

30. Glasser JH. The quality and utility of death certificate data. Am J Public Health 1981;71:231-3.

31. Pérez-Gómez B, Aragonés N, Pollán M, Suárez B, Lope V, Llácer A et al. Accuracy of cancer death certificates in Spain: a summary of available information. Gac Sanit 2006;20(Supl.3):42-51. 32.

32. Martínez C, Sánchez MJ, Rodríguez M, Alamitos FJ, Medina MJ Exactitud del diagnóstico de cáncer en los certificados de defunción de la provincia de Granada. Rev Oncología 2000;2:245-52.

33. Perez-Gomez B, Aragones N, Pollan M, Suarez B, Lope V, Llacer A, et al. Accuracy of cancer death certificates in Spain: a summary of available information. Gac Sanit 2006;20(Supl.3):42-51.

34. Ruiz M, Cirera L, Pérez G, Borrell C, Audica C, Moreno C, et al Comparabilidad entre la novena y la décima revisión de la Clasificación Internacional de Enfermedades aplicada a la codificación de la causa de muerte en España. Gac Sanit 2002;16(6):526-32.

35. Salmerón D, Cirera L, Saez M, Navarro C. Influence of the introduction of the ICD-10 on tendencies of mortality by causes (1980-2004). Gac Sanit 2009;23(2):144-6.

36. Giovannucci E, Wu K. Cancers of the colon and rectum. In: Schottenfeld D, Fraumeni J, editors. Cancer epidemiology and prevention. New York: Oxford University Press; 2006. p. 809-29. 